Georgia State University

ScholarWorks @ Georgia State University

\title{
The Impact of Acceptance and Commitment Training and Multicultural Training on the stigmatizing attitudes and professional burnout of substance abuse counselors
}

\author{
S. C. Hayes \\ R. Bissett \\ N. Roget \\ M. Padilla \\ B. S. Kohlenberg
}

See next page for additional authors

Follow this and additional works at: https://scholarworks.gsu.edu/psych_facpub

Part of the Psychology Commons

\section{Recommended Citation}

Hayes, S. C.; Bissett, R.; Roget, N.; Padilla, M.; Kohlenberg, B. S.; Fisher, G.; Masuda, Akihiko; Pistorello, J.; Rye, A. K.; Berry, K.; and Niccolls, R., "The Impact of Acceptance and Commitment Training and Multicultural Training on the stigmatizing attitudes and professional burnout of substance abuse counselors" (2004). Psychology Faculty Publications. 102.

https://scholarworks.gsu.edu/psych_facpub/102

This Article is brought to you for free and open access by the Department of Psychology at ScholarWorks@ Georgia State University. It has been accepted for inclusion in Psychology Faculty Publications by an authorized administrator of ScholarWorks @ Georgia State University. For more information, please contact scholarworks@gsu.edu. 


\section{Authors}

S. C. Hayes, R. Bissett, N. Roget, M. Padilla, B. S. Kohlenberg, G. Fisher, Akihiko Masuda, J. Pistorello, A. K. Rye, K. Berry, and R. Niccolls 


\begin{abstract}
The Impact of
Acceptance and Commitment Training and Multicultural Training on the Stigmatizing Attitudes and Professional Burnout of Substance Abuse Counselors
\end{abstract}

\author{
Steven C. Hayes, Richard Bissett, \\ Nancy Roget, Michele Padilla, \\ Barbara S. Kohlenberg, Gary Fisher \\ Akihiko Masuda, Jacqueline Pistorello, \\ Alyssa K. Rye, Kristen Berry, and Reville Niccolls \\ University of Nevada, Reno
}

Address editorial correspondence to: Steven C. Hayes Department of Psychology / 296 University of Nevada Reno, NV 89557-0062 


\begin{abstract}
Empirically validated methods for reducing stigma and prejudice toward recipients of behavioral healthcare services are badly needed. In the present study, two packages presented in one day workshops were compared to a biologically oriented Educational Control condition in the alleviation of stigmatizing attitudes in drug abuse counselors. One, Acceptance and Commitment Training (ACT), utilized acceptance, defusion, mindfulness, and values methods. The other, Multicultural Training, sensitized participants to group prejudices and biases. Measures of stigma and burnout were taken pretraining, post-training, and after a three month follow-up. Results showed that Multicultural Training had an impact on stigmatizing attitudes and burnout post-intervention but not at follow-up, but showed better gains in a sense of personal accomplishment as compared to the Educational Control at follow-up. ACT had a positive impact on stigma at follow-up and on burnout at post-treatment and follow-up and follow-up gains in burnout exceeded those of Multicultural Training. ACT also significantly changed the believability of stigmatizing attitudes. This process mediated the impact of ACT but not Multicultural Training on follow-up stigma and burnout. This preliminary study opens new avenues for reducing stigma and burnout in behavioral health counselors.
\end{abstract}

Key Terms: Acceptance and Commitment Therapy, Multicultural Training, stigma, prejudice, burnout, substance abuse counselors 
The Impact of Acceptance and Commitment Training and Multicultural Training on the Stigmatizing Attitudes and Professional Burnout of Substance Abuse Counselors People with behavioral disorders are a heavily stigmatized group (Crisp, Gelder, Nix, Meltzer, \& Rowlands, 2000). Particularly as problems become more severe, stigma is associated with social distancing and withdrawal of access to material supports, such as employment (Corrigan \& Penn, 1999; Penn \& Martin, 1998; Rosenfield, 1997).

There has been relatively little attention paid to the impact of these processes among therapists. Therapists are by role “on the patient’s side” and taken literally, stigmatizing attitudes seem contradictory to that role. Nevertheless, it is known that behavioral health providers often retain negative beliefs about recipients of care (Maslach, Jackson, \& Leiter, 1996).

Beyond negative impacts on clients (Linehan, Cochran, Mar, Levensky, \& Comtois, 2000), entanglement with stigmatizing attitudes may be of considerable direct importance to therapists and their agencies. Professional burnout is a serious problem for workers in behavioral health and other human service professions (Schaufeli, Maslach, \& Marek, 1993). The high turnover rate of behavioral health staff (Liu, 1997) that causes such severe difficulties for treatment programs (Lacoursiere, 2001) is known to be related to burnout (Geurts, Schaufeli, \& De Jonge, 1998; National Drug Abuse Center for Training and Resource Development, 1980), and burnout on the part of therapists reduces patient satisfaction (Garman, Corrigan, \& Morris, 2002).

The psychological effects of working with difficult clients is key feature of burnout (e.g., Sherman \& Thelen, 1998; Shoptaw, Stein, \& Rawson, 2000), particularly when agency support and resources are low (Bradley \& Cartwright, 2002; van Dierendonck, Schaufeli, \& Buunk, 1998). Programs designed to reduce stigmatizing attitudes might thus be of benefit to therapists and the burnout they commonly experience. The present study compared three methods: biologically oriented scientific information about specific forms of substance abuse; Multicultural Training; and Acceptance and Commitment Therapy (ACT; Hayes, Strosahl, \& Wilson, 1999). 
It is frequently claimed that biologically oriented information might be useful in reducing stigma, because that would bolster the idea that behavioral health disorders are diseases (Mehta \& Farina, 1997). In the present study such an educational intervention was used as a comparison condition. This is logical since focused education of this kind is a defining property of the discipline, and therefore if it does actually limit stigma, that benefit is already build into the foundation of the discipline itself.

Perhaps the most widely used method for reducing stigmatization processes in substance abuse counselors is Multicultural Training. Multicultural Training is designed to help counselors become aware of their own biases in such areas as culture, race, ethnicity, family structure, spiritual beliefs, and language. In order to promote more awareness of the client's worldview it is a required part of training for substance abuse counselors in many jurisdictions. Several descriptive studies and quasi-experimental studies have shown that Multicultural Training can reduce counselor's prejudice toward clients from minority cultural groups (e.g., Paradis, 1981; Parker \& McDavis, 1989; Rudolph, 1989), but both outcome and process research are still somewhat limited (Kieselica, Maben, \& Locke, 1999). It is not known if Multicultural Training can reduce stigma toward substance abusers in treatment, but logically it may, since the larger message of Multicultural Training is that each person must be understood in their historical and social context.

Third wave behavior therapy interventions (Hayes, in press) may provide another avenue worth pursuing. These treatments (for book length reviews see Hayes, Follette, \& Linehan, in press, and Hayes, Jacobson, Follette, \& Dougher, 1994) often focus on methods such as acceptance, mindfulness, cognitive defusion, and the like, that hope to reduce the impact of negative thoughts and feelings (e.g., their believability, behavior regulatory functions, and so on) even if their form or frequency changes only slowly or not at all. The same approach seems applicable in this area, particularly because direct attempts to reduce or suppress stigmatizing thoughts are known to produce paradoxical effects (Corrigan, River, Lundin, Penn, Uphoff-Wasowski, \& Campion, 2001; Langer, Fiske, Taylor, \& Chanowitz, 1976; Macrae, Bodenhausen, Milne, \& Jetten, 1994; Smart \& Wegner, 1999, 2000). In the 
present study, ACT was used to teach experiential acceptance, cognitive defusion, mindfulness, and values clarification and its impact on stigma and burnout was examined.

Method

\section{Participants, Assignment, and Treatment Conditions}

This study was conducted as part of the normal continuing education and outreach functions of the Nevada Practice Improvement Collaborative (Nevada PIC) which is associated with the Center for the Application of Substance Abuse Technologies (CASAT) located at the University of Nevada, Reno. Possible participants were randomly selected from master list of licensed or certified alcohol and drug abuse counselors in Nevada. Those currently working for an agency that received funding from the Nevada Bureau of Alcohol and Drug Abuse (BADA) were eliminated in order to avoid contamination by other studies being conducted at those agencies. Possible participants were then randomly assigned to each of the three conditions. 115 counselors were sent a letter of invitation for each workshop. Of these 35 signed up and 30 attended for ACT, 42 signed up and 34 attended for the multicultural, and 41 signed up and 29 attended for the methamphetamine training.

Participants were told that the study was designed to reduce counselor burnout and the level of stigmatizing attitudes and beliefs towards individuals who use substances. Methamphetamine and ecstasy (MDMA) training emphasized the role of biological factors in addiction and its treatment (termed here the “educational control” condition); Multicultural Training emphasized the role of culture, race, ethnicity, family structure, spiritual beliefs, and language; ACT emphasized the role of psychological barriers to constructive client engagement. All three were geared exclusively toward substance abuse therapists.

In all three conditions, the interventions consisted of a day-long workshop (total contact time of six hours) lead by Master's or Doctoral level professionals. Those conducting the Multicultural Training included professionals from ethnic minorities. Those conducting the Methamphetamine and ecstasy (MDMA) training included a psychiatrist. 
Acceptance and Commitment Training (ACT). This condition is termed "Acceptance and Commitment Training” here in order to distinguish the protocol from similar protocols used for psychotherapy purposes, but it has been deliberately named so that the same acronym applies, since training consisted of material drawn from the psychotherapy manual (Hayes et al., 1999). Emphasis was placed on the view that entanglement with negative evaluated thoughts is built into human language. Specific exercises encouraged participants to notice how automatic this process is (e.g., in categorizing others in the room). Participants were taught methods of reducing the impact and believability of negative thoughts even if they continue to occur, through acceptance, mindfulness, and cognitive defusion. Exercises such as repeating a word until it lost all meaning (Titchener, 1916, p. 245) were used to create more psychological distance between the participants and their thoughts. Several exercises were used that deliberately brought up difficult emotions and thoughts about clients and the group practiced experiencing these private reactions without believing or disbelieving them, and without avoiding them. Finally, participants were guided through the nature and importance of values and went through public values declaration exercises.

Multicultural Training. The cultural diversity training condition included a mixture of group activities, discussion, and didactic presentation designed to sensitize participants to the stigmatizing effects of cultural bias. The multicultural conditions covered following topics: (a) cultural diversity (b) cultural competence in therapy work, (c) awareness of one’s own values and biases while working with clients, (d) awareness of the client's worldview, and (e) culturally appropriate intervention strategies. The role of diversity in a variety of life domains (e.g., race, ethnicity, gender, age, religion, sexual orientation) was identified. Participants were asked to identify their values and biases and to examine the impact of these processes on their attitudes, beliefs, and feelings towards themselves and others. Small group exercises were used to help the participants apply the didactic material. The group was given practice in seeing arguments from others perspectives, using a set of controversial statements that group members were arbitrarily assigned to argue either "Pro" or "Con”. The importance of treating 
clients without stigma or prejudice, but rather as human beings with their own particular historical and social background was emphasized.

Educational Control. The Educational Control condition was a day-long didactic lecture that focused on scientific and biological information about methamphetamine and MDMA, and the resulting disease of addiction to these drugs. Other drugs, such as hallucinogens, were covered briefly. The lecture was divided into five content areas: (a) a history of drug abuse and the passage of trafficking laws, (b) historical and current prevalence of methamphetamine and MDMA use, (c) the chemical and neurobiological properties of these drugs, (d) clinical issues related to these drugs, and (e) available interventions for substance use disorders. In addition to the presentation, several articles were distributed that covered scientific findings and epidemiological reports on the use of methamphetamines and MDMA and their impact on the brain and behavior.

\section{Assessment}

\section{Administration of Assessments}

Participants were assessed at the beginning of the day-long workshop (pre), at the end of the workshop (post), and at 3-month follow-up. Follow-up assessments were mailed to participants and were returned by 26 (87\%), 32 (94\%), and 27 (93\%) participants in the ACT, Multicultural Training, and Educational Control groups, respectively. Participants filled out the baseline and post-training assessments at the training site, and thus with the exception of occasional skipped questionnaires all participants completed these assessments.

\section{Instruments}

Primary outcome measure. No measure of stigmatizing attitudes toward substance abusers is currently available. The primary outcome measure, the Community Attitudes Toward Substance Abusers (CASA) was created by our research team by modifying the Community Attitudes toward the Mentally Ill scale (CAMI; 40 items; Taylor \& Dear, 1981): a previously validated 7-point Likert, self-report questionnaire, designed to measure the occurrence of stigmatizing attitudes toward the mentally ill, with 
good reliability and validity (Taylor \& Dear, 1981). Items of the CAMI were modified to apply to substance abusers as follows. The term "the mentally ill" was substituted with the term "drug addicts and alcoholics,” "mental illness" with "drug and alcohol addictions," "mental disturbance" with "drug and alcohol addictions," and gender specific references (e.g., "a woman") with "a person." Examples of CASA item are "A person would be foolish to marry someone who had a drug or alcohol addiction, even though that person seems fully recovered” or "One of the main causes of drug and alcohol addiction is a lack of self-discipline and will power.” The CAMI (and thus the CASA) has four subscales: Benevolence, Social Restrictiveness, Community approach, and Authoritarianism, which can be combined into a total score. Authoritarianism required the removed of one item that did not translate well from the CAMI. Baseline results revealed the following alpha coefficients: Benevolence - .75, Social Restrictiveness $=.78$, Community Approach - .92, and Authoritarianism - .63. Scale intercorrelations in baseline varied from -.35 to -.58. The total score formula reverses Benevolence and Community Approach and thus higher scores indicate higher levels of stigmatization.

Secondary outcome measure. The secondary outcome measure was the Maslach Burnout Inventory (MBI). The MBI (Maslach et al., 1996) is the widest used burnout inventory and its factor structure, reliability, and validity have received good support across many types of employment, including behavioral health professions (e.g., Bakker, Demerouti, \& Schaufeli, 2002). Each of 22 items is rated on a 7-point Likert Scale (from $0=$ "never" to 6 = "everyday"). An overall burnout score can be generated by combining items on emotional exhaustion (feelings of being emotionally overextended and exhausted by one's work) and depersonalization (impersonal attitudes toward recipients of care). The Personal Accomplishment subscale assesses feelings of competence and successful achievement of one's work with people and must be treated as a separate scale.

ACT process measure: Stigmatizing Attitudes - Believability (SAB). A final measure was constructed to assess a process primarily targeted by the ACT protocol in the present study: the believability of negative thoughts toward clients, as distinct from their form, frequency, or situational 
sensitivity. Previous studies (e.g., Bach \& Hayes, 2002; Zettle \& Hayes, 1986) have shown that ACT quickly reduces the believability or impact of negative thoughts even when their form or frequency continues unaltered. ACT has been argued to work through this process, which is termed "cognitive defusion.” In order to measure it in the present study, a list of 20 common negative thoughts about consumers with substance use problems was generated from substance abuse treatment providers (not those in the present study). Examples include "my client is not going to change no matter what I do" and “If my clients really wanted to get sober, they would.” Participants were asked to "imagine that the following thoughts occurred to you right now” and, if they occurred, how believable they would be on a 7-point Likert scale (from 1 = "not at all believable” to 7 = “completely believable”). Item responses are summed to an overall score ranging from 20 to 140. Higher scores indicate a greater level of "cognitive fusion” with stigmatizing thoughts. Baseline data showed that the SAB had adequate internal consistency (alpha $=.78$ ). It was predicted that the effect of ACT but not Multicultural Training would be mediated by this measure.

\section{Results}

\section{Characteristics of Sample}

Of the total of 90 participants, $63 \%$ were female, $84 \%$ were Caucasian, and $76 \%$ reported that their primary discipline was addictions counseling. The average participant was 53 years of age and 54\% had at least a Master's degree. All participants were certified or licensed in the addiction field, 57\% had more than 10 years of experience in addictions services, and 53\% worked as an addiction counselor for twenty hours or more per week. Most of the participants (55\%) worked in outpatient or private practice settings; 61\% were line staff. Case loads were as follows: more than 31 a week (29\%), 21 to 30 cases (18\%), 11 to 20 cases (27\%), and $1-10$ cases (26\%).

\section{Initial Group Differences and Analytic Strategy}

Means and standards deviations for all variables reported here are shown in Table 1. Pairwise comparisons among all conditions using contrast analyses on all outcome and process measures at 
baseline revealed no significant group differences. In the first primary analyses, the data set was characterized by a repeated measures analysis of variance on the pre, post and follow-up scores for the three intervention conditions. To avoid listwise deletion, missing data was replaced with the last value carried forward or by the phase mean for pre measures. To assess changes within each of the treatment conditions paired-samples t tests were conducted comparing pre scores to post scores and pre scores to follow-up scores. Finally, a priori contrasts were calculated between each active treatment group and the control condition, and between the two treatment groups using the difference scores from pre to post and from pre to the three month follow-up (not assuming equal variances). Post scores were not compared to follow-up scores because it seemed practically uninteresting, given that post-scores were collected 6 hours after pre-scores.

\section{Effects on Stigma}

The primary outcome analysis looked at stigmatizing attitudes, as measures by the CASA. A repeated measures ANOVA showed no effect for time, but found a significant time by condition interaction $(F(4,180)=3.16, p=.015)$. Paired-samples t tests showed a significant worsening for the Educational Control condition ( $t(28)=-2.50, p=.019$ ), but no significant changes for the other two groups. Comparing across conditions, Multicultural Training improved more than the Educational Control condition from pre to post treatment $(t(56)=-2.41, p=.019)$ but ACT did not. Conversely, ACT improved significant more than the Educational Control condition from pre treatment to follow-up $(t(56)=-2.63, p=011)$ but Multicultural Training did not. These results are shown in Figure 1 .

Insert Figure 1 and Table 1 About Here

\section{Effects on Burnout}

The secondary outcome analysis looked at overall burnout and sense of accomplishment, as measured by the MBI. Overall burnout showed a significant time $\mathrm{x}$ treatment interaction $(F(4,180)=$ 4.05, $p=.004)$. Paired-sample t tests showed a significant improvement in burnout within the ACT 
condition at post $(t(29)=3.01, p=.005)$ and follow-up $(t(29)=2.70, p=.012)$. The Multicultural Training condition improved at post $(t(33)=2.33, p=.026)$ but not follow-up. The Educational Control condition did not change. Comparing across conditions, at post ACT was significantly better than the Educational Control condition $(t(36)=2.44, p=.02)$ and the Multicultural Training condition was marginally better than the Educational Control condition $(t(32)=2.01, p=.053)$. At follow-up, ACT was better than Multicultural Training $(t(60)=2.72, p=.008)$. Other comparisons were not significant.

The scores on Personal Accomplishment showed a significant time by condition interaction ( $F$ $(4,180)=2.60, p=.038)$. Paired-samples t tests showed that participants in the Educational Control condition worsened significantly at follow-up $(t(29)=-2.33, p=.027$; note that items are reverse scores so that higher scores equal a lower sense of accomplishment). Neither of the other groups showed significant changes. Comparing across conditions, there were no differences at post. At follow-up Multicultural Training difference scores were better than the Educational Control condition $(t(51)=$ 2.74, $p=.009)$. No other comparisons were significant.

\section{Process Analyses}

The primary ACT process measure in this study was the SAB, which measured decreases in the believability of negative thoughts, given that they occurred. We first looked to see whether the SAB changed in a coherent fashion, by conducting the same analysis as was used with outcome measures. A marginally significant time $\mathrm{x}$ treatment interaction was obtained $(F(4,180)=2.18, p=.073)$. Pairedsamples t tests showed that participants in the ACT condition showed significantly lower levels of believability of stigmatizing thoughts at post treatment $(t(29)=2.31, p=.028)$, and continued to do so at follow-up $(t(29)=2.48, p=.019)$. The Educational Control condition did not show any significant changes in this process post treatment, or at follow-up. The Multicultural Training group showed an improvement at post $(t(33)=2.40, p=.022)$ but not follow-up. Comparing across conditions, ACT showed significantly lower SAB difference scores than did the Educational Control condition from pre to post treatment $(t(53)=-2.12, p=.038)$ and pre to follow-up $(t(56)=-2.73, p=.008)$. The 
Multicultural Training group also showed significantly lower SAB difference scores than did the Educational Control condition from pre to post treatment $(t(55)=-2.26, p=.028)$ but not from pre to follow-up. This shows that ACT did significantly influence the process it targets. These data are shown in Figure 2.

Insert Figure 2 About Here

Four mediational analyses were then conducted examining the mediating role of the SAB in stigma and overall burnout results produced by the ACT and Multicultural conditions. The model suggested by MacKinnon (2003) was used which requires 1) a Spearman above .2 between treatment condition and outcome; 2) a significant Spearman between treatment condition and the mediator, 3) a significant Spearman between the mediator and the outcome, and 4) a significant regression between the mediator and the outcome after condition is included in the model. This approach is preferable in this case to those of Baron and Kenny (1986) because their methods are known to be under powered for smaller studies (MacKinnon, Lockwood, Hoffman, West, \& Sheets, 2002). MacKinnon’s method is more powerful because it is largely non-parametric and does not make the same level of assumptions about treatment impact and the need for full mediation.

The first two analyses examined follow-up SAB scores as related to follow-up burnout scores, first with ACT versus the Control group and then with Multicultural Training versus the Control. With ACT, MacKinnon's Conditions 1 (Spearman $=.28, p=.03), 2($ Spearman $=.28, p=.03)$, and 3 $($ Spearman $=.22, p=.035)$ were met; Condition 4 was marginally met $(\mathrm{B}=.22$, $\mathrm{SE}=.11, t=1.95, p=$ .056). With Multicultural Training, no conditions were met: 1 (Spearman $=.03, p=n s), 2$ (Spearman $=$ $.11, p=\mathrm{ns}), 3$ (Spearman $=.18, p=\mathrm{ns})$, nor $4(\mathrm{~B}=.18, \mathrm{SE}=.12, t=1.58, p=\mathrm{ns})$. A similar analysis was then conducted on the follow-up CASA scores, again examining the SAB as a mediator. In the ACT versus Control comparison, all conditions were met: 1 (Spearman $=.28, p=.03$ ), 2 (shown above), 3 $($ Spearman $=.43, p=.001)$ and $4(\mathrm{~B}=.59, \mathrm{SE}=.20, t=2.97, p=.004)$. In the Multicultural Training 
versus Control comparison, Condition 1 was not met (Spearman $=.17, p=n s$ ), nor was 2 (shown above), 3 was (Spearman $=.32, p=.01)$, and 4 was $(\mathrm{B}=.49$, $\mathrm{SE}=.20, t=2.50, p=.015)$. Overall, this pattern of results suggests that the believability of stigmatizing attitudes may function as a mediator of ACT’s impact, but not Multicultural Training's impact, on stigma and burnout.

\section{Discussion}

Many forms of stigma are matters of ignorance, but others are more deeply ingrained, culturally conditioned, or perhaps even built into biasing processes that are part of human language and cognition itself. There is a growing set of social psychological interventions for stigma that are known to be helpful, such as ensuring interpersonal contact (for recent reviews see Corrigan, 2002; Couture \& Penn, 2003), or providing accurate information about dangerousness and other issues (Penn, Kommana, Mansfield, \& Link, 1999), but these interventions seem to be of limited relevance to therapists, who already have extensive information and contact.

The present study shows that existing training and therapy methods may be of help in this situation, a finding that comports with the work of others (e.g., Linehan et al., 2000). To the extent that there is a connection between promotion of psychological health and the pressing social issues of tolerance, stigma, and prejudice (e.g., Hayes, Niccolls, Masuda, \& Rye, 2002) it is possible that a wide variety of empirically supported therapies could also be helpful in this regard.

Multicultural Training, which is a well established method that is widely used in the mental health and substance abuse fields, had at least an initially positive effect on stigmatizing processes. In general the effects of Multicultural Training tended to be less consistent at follow-up than at post assessment, but given that multicultural knowledge is important for treatment providers on other grounds these results are still encouraging.

The effects on burnout are also positive, although only the effects at follow-up seem to be of practical importance, and these were limited to the continued improvement of ACT participants and their superiority over those in the Multicultural condition, not the Control condition. It is too harsh to 
conclude that Multicultural Training is unhelpful over the long term, however, particularly because some positive follow-up differences with the Control condition remained (i.e., in accomplishment). It could be, however, that the cultural information in Multicultural Training added rules about stigmatized groups that, while having initially positive effects on belief content, tended gradually to exacerbate a sense of shame or guilt when stigmatizing thoughts were noticed. If such a process were at work, the believability of these thoughts might initially be suppressed, only to return over time as suppressive effects increase their literal importance. The SAB results provide some support for this possibility within the Multicultural condition. If so, a combined ACT / Multicultural Training condition might be helpful: Multicultural Training would help provided needed cultural information while ACT would prevent its psychological misuse. It should be noted that there were no measures in the current study on multicultural competence per se - it seems highly likely that Multicultural Training, which is primarily oriented toward this domain, would be superior in this area. If a combined treatment was successful, a broader set of positive outcomes might be possible than with either training technology alone.

A particularly positive aspect of a beginning study like this is evidence that the processes of change predicted by ACT theory helped explain the impact of ACT but not Multicultural Training on stigma and burnout at follow-up. It seems doubtful that a six hour workshop will be enough to put a very large permanent dent into either burnout or stigma, so undoubtedly a great deal of technological development will still be needed. This process result provides reassurance that procedures aimed at defusion and acceptance rather than direct change might be usefully explored as methods of reducing stigma and burnout. It that regard it is also hopeful that more extensive versions of ACT have already been shown to have long term and overtly behavioral impacts in the workplace (e.g., Bond \& Bunce, 2000). Given the seriousness of the burnout problem among health professionals, particularly among substance abuse counselors, it thus may now make sense to test more elaborate versions of this technology in larger, more extended studies. Infrastructure studies show enormous turnover and burnout among drug and alcohol counselors and administrators (e.g., McLellan, Carise, \& Kleber, 2003) 
at the very time that states are professionalizing the area and demanding ever higher levels of accountability, empirical focus, and training. Most burnout intervention programs have limited research supporting them (Schaufeli et al., 1993) and the more impactful programs are quite extensive (e.g., van Dierendonck et al., 1998). There is much room for improvement, and the behavior therapies may be able to be of help.

The present study has several notable weaknesses that will have to be rectified before it can be said for certain that either of these methods have specific effects in the area of stigma or burnout. It is quite small and thus has limited power. Participants were randomly assigned to be offered specific forms of training, but they knew of the specific workshop and only about 1/3 accepted, which could readily lead to selection biases with unknown impact. Cross contamination was not controlled since therapists in the same work setting could be assigned to different conditions. The perceived relevance of methods studied varied: two of the treatment conditions were obviously about stigma while the other was more narrowly focused and rather indirectly relevant to the issue through its support for a biological model of addiction. Follow-up was both short and entirely self-report: no measures of absenteeism, turn-over, client outcome, client satisfaction, and the like were taken. The self-report measures used had fairly high face validity, which makes demand-based interpretations plausible until better controls and additional measures have been included. Some of these measures were constructed for the study and have limited psychometric information, and many require further development. Well-known and empirically tested methods of burnout reduction, such as stress inoculation (e.g., Freedy \& Hobfoll, 1994) were not included, so we do not yet know if ACT or Multicultural Training are competitive in their impact on burnout. The initial level of burnout was not very high among these participants, which could limit the applicability of these results in that area. Finally, these interventions were real-world continuing education workshops and differed on many dimensions that it might be important (e.g., workshop leaders differed across groups; the amount of audience discussion was large in the psychosocial interventions but was limited in the educational intervention; and so on). 
Nevertheless, this study does show the possible relevance of the behavioral and cognitive therapies to social issues of this kind. In a post 9-11 world, having new methods to deal with prejudice seems crucial, and stigma seems to be a readily accessible form of prejudice. The rise of terrorism can be thought of at least in part as a rise in intolerance. If so, any "war on terrorism" should include a "war on intolerance” but it is behavioral scientists, not military experts, who need to learn how to fight that war. The present data suggest that working on our own biases as therapists may provide a readily available arena for such work, and one that may reap immediate collateral benefits. 


\section{References}

Bach, P. \& Hayes, S. C. (2002). The use of Acceptance and Commitment Therapy to prevent the rehospitalization of psychotic patients: A randomized controlled trial. Journal of Consulting and Clinical Psychology, 70, 1129-1139.

Bakker, A. B., Demerouti, E. \& Schaufeli, W. B. (2002). Validation of the Maslach Burnout Inventory--General Survey: An internet study. Anxiety, Stress and Coping, 15, 245-260.

Baron, R. M. \& Kenny, D. A. (1986). The moderator-mediator variable distinction in social psychological research: Conceptual, strategic, and statistical considerations. Journal of Personality \& Social Psychology, 51, 1173-1182.

Bond, F. W. \& Bunce, D. (2000). Mediators of change in emotion-focused and problem-focused worksite stress management interventions. Journal of Occupational Health Psychology, 5, 156-163.

Bradley, J. R., \& Cartwright, S. (2002). Social support, job stress, heath, and job satisfaction among nurses in the United Kingdom. International Journal of Stress Management, 9, 163-182.

Corrigan, P.W. (2002). Testing social cognitive models of mental illness stigma: the prairie state stigma studies. Psychiatric Rehabilitation Skills, 6(2), 232-254.

Corrigan, P. W., \& Penn, D. L. (1999) Lessons from social psychology on discrediting psychiatric stigma. American Psychologist, 54, 765-776.

Corrigan, P. W., River, L., P., Lundin, R. K., Penn, D. L., Uphoff-Wasowski, K. Campion, J., Mathisen, J., Gagnon, C., Bergman, M., Goldstein, H., \& Kubiak, M. A. (2001). Three strategies for changing attributions about severe mental illness. Schizophrenia Bulletin, 27, 187-195.

Couture, S. M., \& Penn, D. L. (2003). Interpersonal contact and the stigma of mental illness: A review of the literature. Journal of Mental Health, 12, 291-305.

Crisp, A. H., Gelder, M. G., Nix, S., Meltzer, H. I., \& Rowlands, O.J. (2000). Stigmatisation of people with mental illnesses. British Journal of Psychiatry, 177, 4-7. 
Freedy, J. R., \& Hobfoll, S. E. (1994). Stress inoculation for reduction of burnout: A conservation of resources approach. Anxiety, Stress, and Coping: An International Journal, 6, 211-325.

Garman, A. N., Corrigan, P. W., \& Morris, S. (2002). Staff burnout and patient satisfaction: Evidence of relationships at the care unit level. Journal of Occupational Health Psychology, 7(3), 235241.

Geurts, S., Schaufeli, W., \& De Jonge, J. (1998). Burnout and intention to leave among mental health-care professionals: A social psychological approach. Journal of Social \& Clinical Psychology, 17, 341-362.

Hayes, S. C. (in press). Acceptance and Commitment Therapy, Relational Frame Theory, and the third wave of behavior therapy. Behavior Therapy.

Hayes, S. C., Follette, V. M., \& Linehan, M. (in press). Mindfulness, acceptance, and relationship: Expanding the cognitive behavioral tradition. New York: Guilford Press.

Hayes, S. C., Jacobson, N. S., Follette, V. M. \& Dougher, M. J. (Eds.) (1994). Acceptance and change: Content and context in psychotherapy. Reno, NV: Context Press.

Hayes, S. C., Niccolls, R., Masuda, A., \& Rye, A. K. (2002). Prejudice, terrorism, and behavior therapy. Cognitive and Behavioral Practice, 9, 296-301.

Hayes, S. C. Strosahl, K. D., \& Wilson, K. G. (1999). Acceptance and Commitment Therapy: An experiential approach to behavior change. New York: Guilford Press.

Kiselica, M. S., Maben, P., \& Locke, D. C. (1999). Do multicultural education and diversity appreciation training reduce prejudice among counseling trainees? Journal of Mental Health Counseling, 21, 240-254.

Lacoursiere, R. B. (2001). "Burnout" and substance user treatment: The phenomenon and the administrator-clinician's experience. Substance Use \& Misuse, 36, 1839-1874.

Langer, E. J., Fiske, S., Taylor, S.E., \& Chanowitz, B. (1976). Stigma, staring, and discomfort: A novel-stimulus hypothesis. Journal of Experimental Social Psychology, 12, 451-463. 
Linehan, M. M., Cochran, B. N., Mar, C. M., Levensky, E. R., \& Comtois, K. A. (2000). Therapeutic burnout among borderline personality disordered clients and their therapists: Development and evaluation of two adaptations of the Maslach Burnout Inventory. Cognitive and Behavioral Practice, 7, 329-337.

Liu, H. (1997). Burnout and organizational commitment among staff of publicly funded substance user treatment program. Doctoral Dissertation, University of Maryland, Baltimore.

Macrae, C. N., Bodenhausen, G. V., Milne, A. B., \& Jetten, J. (1994). Out of mind but back in sight: Stereotypes on the rebound. Journal of Personality \& Social Psychology, 67, 808-817.

Maslach, C., Jackson, S. E, \& Leiter, M. P. (1996). Maslach Burnout Inventory._(3rd ed.). Palo Alto, CA: Consulting Psychologists Press.

MacKinnon, D. P. (November 2003). Mediator and moderator methods. Paper presented at the meeting of the Association for the Advancement of Behavior Therapy, Boston, MA.

MacKinnon, D. P., Lockwood, C. M., Hoffman, J. M., West, S. G., Sheets, V. (2002). A comparison of methods to test mediation and other intervening variable effects Psychological Methods, 7 (1), 83-104.

McLellan, A. T., Carise, D., \& Kleber, H. D. (2003). Can the national addiction treatment infrastructure support the public's demand for quality care? Journal of Substance Abuse Treatment, 25(2), 117-121.

Mehta, S. \& Farina, A. (1997). Is being "sick" really better? Effect of the disease view of mental disorder on stigma. Journal of Social and Clinical Psychology, 16, 405-419.

National Drug Abuse Center for Training and Resource Development. (1980). Staff burnout: Training manual. (National Institute on Drug Abuse Publication No. 80-00115). Washington, DC: Author.

Paradis, F. E. (1981). Themes in the training of culturally effective psychotherapists. Counselor Education and Supervision, 21, 134-156. 
Parker, W. M., \& McDavis, R. J. (1989). An awareness experience: Toward counseling minorities. Counselor Education and Supervision, 19, 312-317.

Penn, D. L., Kommana, S., Mansfield, M. \& Link, B. G. (1999). Dispelling the stigma of schizophrenia: II. The impact of information on dangerousness. Schizophrenia Bulletin, 25, 437-446.

Penn, D. L., \& Martin, J. (1998). The stigma of severe mental illness: Some potential solutions for a recalcitrant problem. Psychiatric Quarterly. Special Issue: New frontiers in the psychiatric rehabilitation of schizophrenia, 69, 235-247.

Rosenfield, S. (1997). Labeling mental illness: The effects of received services and perceived stigma on life satisfaction. American Sociological Review, 62, 660-672.

Rudolph, J. (1989). Effects of a workshop on mental health practitioners' attitudes toward homosexuality and counseling effectiveness. Journal of Counseling and Development, 68, 81-85.

Schaufeli, W. B., Maslach, C., \& Marek, T. (Eds.). (1993). Professional burnout: Recent developments in theory and research. Philadelphia, PA; Taylor and Francis.

Sherman, M. D., \& Thelen, M. H. (1998). Distress and professional impairment among psychologists in clinical practice. Professional Psychology: Research and Practice, 29, 79-85.

Shoptaw, S., Stein, J. A., \& Rawson, R. A. (2000). Burnout in substance abuse counselors: Impact of environment, attitudes, and clients with HIV. Journal of Substance Abuse Treatment, 19, 117126

Smart, L., \& Wegner, D. M. (1999). Covering up what can't be seen: Concealable stigma and mental control. Journal of Personality and Social Psychology, 77, 474-486.

Smart, L. \& Wegner, D. M. (2000). The hidden costs of hidden stigma In T. F. Heatherton and R. E. Kleck (Eds.), The social psychology of stigma (pp. 220-242). New York: Guilford Press.

Taris, T. W., Peeters, M. C. W., Le Blanc, P. M., Schreurs, P. J. G. \& Schaufeli, W. B. (2001). From inequity to burnout: The role of job stress. Journal of Occupational Health Psychology, 6, 303323 
Taylor, S. M., \& Dear, M. J. (1981). Social community attitudes toward the mentally ill. Schizophrenia Bulletin, 7, 225-240.

Titchener, E. B. (1916). A text-book of psychology. New York: MacMillan.

van Dierendonck, D., Schaufeli, W. B., \& Buunk, B. P. (1998). The evaluation of an individual burnout intervention program: The role of inequity and social support. Journal of Applied Psychology, 83, 392-407.

Zettle, R. D. \& Hayes, S. C. (1986). Dysfunctional control by client verbal behavior: The context of reason giving. The Analysis of Verbal Behavior, 4, 30-38. 


\section{Authors Footnotes}

Requests for reprints should be addressed to Steven C. Hayes, Department of Psychology / 296, University of Nevada, Reno, NV 89557-0062

The present project was funded by a grant from the Center for Substance Abuse Treatment, Substance Abuse and Mental Health Services Administration, Grantee TI12899. This project was designed and implemented as part of the Nevada Practice Improvement Collaborative. The authors would like to thank Dr. Susan Doctor, Leslie Steve, Dr. John Chappel, Garry Rubinstein, and Casey Sackett for their help with this study. 
Table 1. Means, N, and Standard Deviations for Primary Study Variables

\begin{tabular}{|c|c|c|c|c|}
\hline & $S A B$ & CASA & $\begin{array}{c}\text { Burnout } \\
\text { (Depersonalization } \\
\text { plus Exhaustion) }\end{array}$ & Accomplishment \\
\hline \multicolumn{5}{|c|}{ Acceptance and Commitment Training } \\
\hline Pre & $\begin{array}{l}M=61.50 \\
S D=14.76 \\
N=30\end{array}$ & $\begin{array}{l}\mathrm{M}=-47.97 \\
\mathrm{SD}=21.81 \\
\mathrm{~N}=30\end{array}$ & $\begin{array}{l}\mathrm{M}=17.87 \\
\mathrm{SD}=12.15 \\
\mathrm{~N}=30\end{array}$ & $\begin{array}{l}\mathrm{M}=5.47 \\
\mathrm{SD}=4.86 \\
\mathrm{~N}=30\end{array}$ \\
\hline Post & $\begin{array}{l}M=57.50 \\
S D=16.04 \\
N=30\end{array}$ & $\begin{array}{l}\mathrm{M}=-49.57 \\
\mathrm{SD}=26.43 \\
\mathrm{~N}=30\end{array}$ & $\begin{array}{l}\mathrm{M}=15.20 \\
\mathrm{SD}=10.99 \\
\mathrm{~N}=30\end{array}$ & $\begin{array}{l}\mathrm{M}=6.23 \\
\mathrm{SD}=5.36 \\
\mathrm{~N}=30\end{array}$ \\
\hline Follow-up & $\begin{array}{l}M=56.40 \\
S D=16.18 \\
N=30\end{array}$ & $\begin{array}{l}\mathrm{M}=-55.77 \\
\mathrm{SD}=26.76 \\
\mathrm{~N}=30\end{array}$ & $\begin{array}{l}M=14.83 \\
S D=9.95 \\
N=30\end{array}$ & $\begin{array}{l}\mathrm{M}=5.67 \\
\mathrm{SD}=5.42 \\
\mathrm{~N}=30\end{array}$ \\
\hline Multicultu & I Training & & & \\
\hline Pre & $\begin{array}{l}M=62.82 \\
S D=16.70 \\
N=34\end{array}$ & $\begin{array}{l}\mathrm{M}=-44.24 \\
\mathrm{SD}=25.92 \\
\mathrm{~N}=34\end{array}$ & $\begin{array}{l}\mathrm{M}=19.68 \\
\mathrm{SD}=11.49 \\
\mathrm{~N}=34\end{array}$ & $\begin{array}{l}\mathrm{M}=6.84 \\
\mathrm{SD}=5.05 \\
\mathrm{~N}=34\end{array}$ \\
\hline Post & $\begin{array}{l}M=58.03 \\
S D=16.78 \\
N=34\end{array}$ & $\begin{array}{l}\mathrm{M}=-49.24 \\
\mathrm{SD}=29.50 \\
\mathrm{~N}=34\end{array}$ & $\begin{array}{l}\mathrm{M}=18.24 \\
\mathrm{SD}=12.24 \\
\mathrm{~N}=34\end{array}$ & $\begin{array}{l}\mathrm{M}=6.91 \\
\mathrm{SD}=5.90 \\
\mathrm{~N}=34\end{array}$ \\
\hline Follow-up & $\begin{array}{l}M=62.21 \\
S D=16.65 \\
N=34\end{array}$ & $\begin{array}{l}\mathrm{M}=-47.65 \\
\mathrm{SD}=26.93 \\
\mathrm{~N}=34\end{array}$ & $\begin{array}{l}\mathrm{M}=21.62 \\
\mathrm{SD}=13.64 \\
\mathrm{~N}=34\end{array}$ & $\begin{array}{l}\mathrm{M}=5.85 \\
\mathrm{SD}=4.24 \\
\mathrm{~N}=34\end{array}$ \\
\hline
\end{tabular}




\begin{tabular}{|c|c|c|c|c|}
\hline \multicolumn{5}{|c|}{ Educational Control } \\
\hline Pre & $\begin{array}{l}\mathrm{M}=62.28 \\
\mathrm{SD}=14.05 \\
\mathrm{~N}=29\end{array}$ & $\begin{array}{l}\mathrm{M}=-43.45 \\
\mathrm{SD}=24.44 \\
\mathrm{~N}=29\end{array}$ & $\begin{array}{l}\mathrm{M}=22.86 \\
\mathrm{SD}=12.14 \\
\mathrm{~N}=29\end{array}$ & $\begin{array}{l}\mathrm{M}=6.06 \\
\mathrm{SD}=3.89 \\
\mathrm{~N}=29\end{array}$ \\
\hline Post & $\begin{array}{l}M=63.00 \\
S D=15.15 \\
N=29\end{array}$ & $\begin{array}{l}\mathrm{M}=-39.14 \\
\mathrm{SD}=23.80 \\
\mathrm{~N}=29\end{array}$ & $\begin{array}{l}\mathrm{M}=26.28 \\
\mathrm{SD}=18.01 \\
\mathrm{~N}=29\end{array}$ & $\begin{array}{l}\mathrm{M}=6.79 \\
\mathrm{SD}=5.21 \\
\mathrm{~N}=29\end{array}$ \\
\hline Follow-up & $\begin{array}{l}\mathrm{M}=64.69 \\
\mathrm{SD}=15.81 \\
\mathrm{~N}=29\end{array}$ & $\begin{array}{l}\mathrm{M}=-39.21 \\
\mathrm{SD}=24.54 \\
\mathrm{~N}=29\end{array}$ & $\begin{array}{l}\mathrm{M}=23.24 \\
\mathrm{SD}=16.88 \\
\mathrm{~N}=29\end{array}$ & $\begin{array}{l}\mathrm{M}=8.41 \\
\mathrm{SD}=6.12 \\
\mathrm{~N}=29\end{array}$ \\
\hline
\end{tabular}




\section{Figure Captions}

Figure 1. CASA total scores at pre, post, and follow-up for ACT, Multicultural Training, and the Educational Control condition.

Figure 2. SAB total scores at pre, post, and follow-up for ACT, Multicultural Training, and the Educational Control condition. 
Figure 1

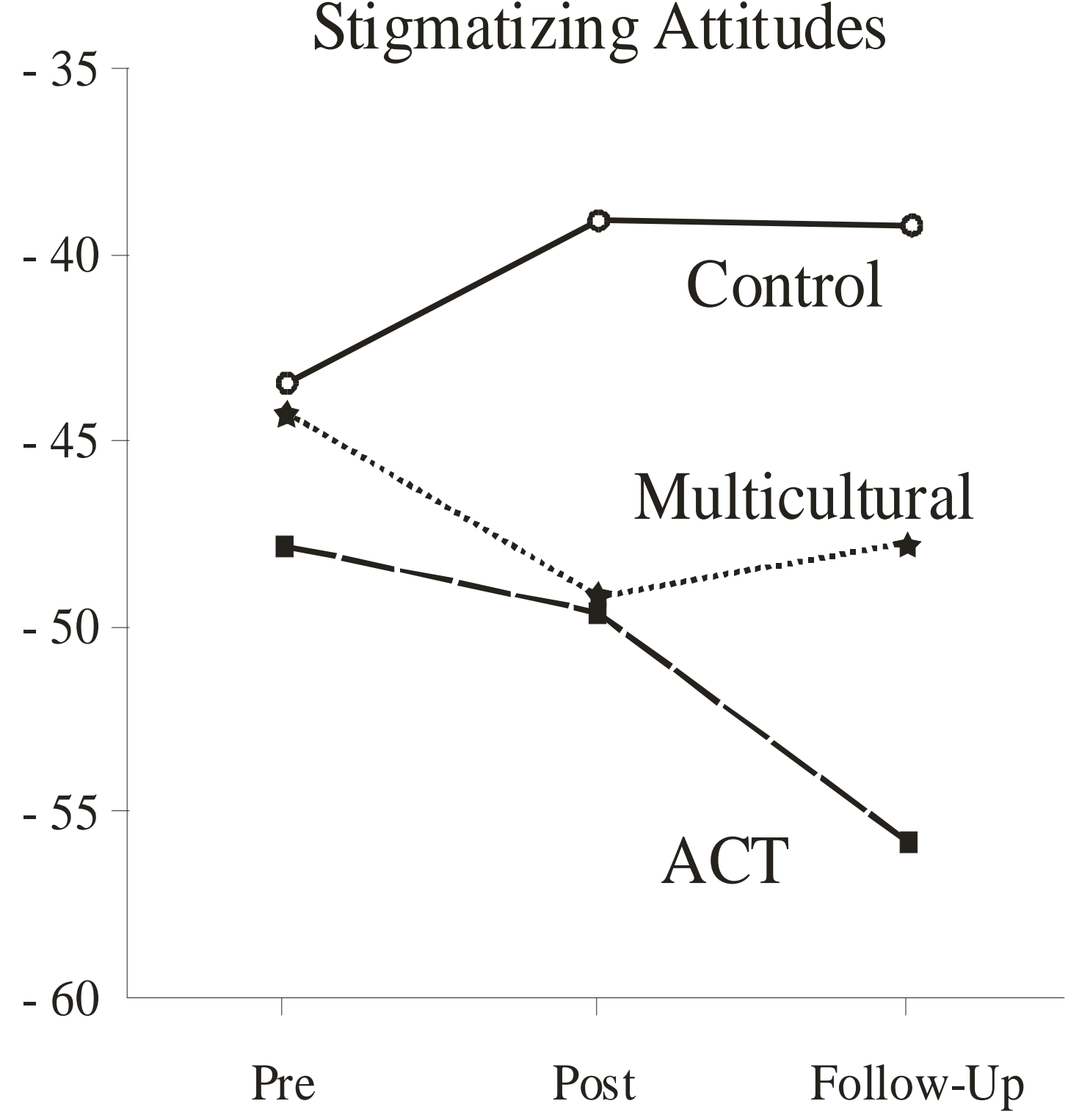


Figure 2

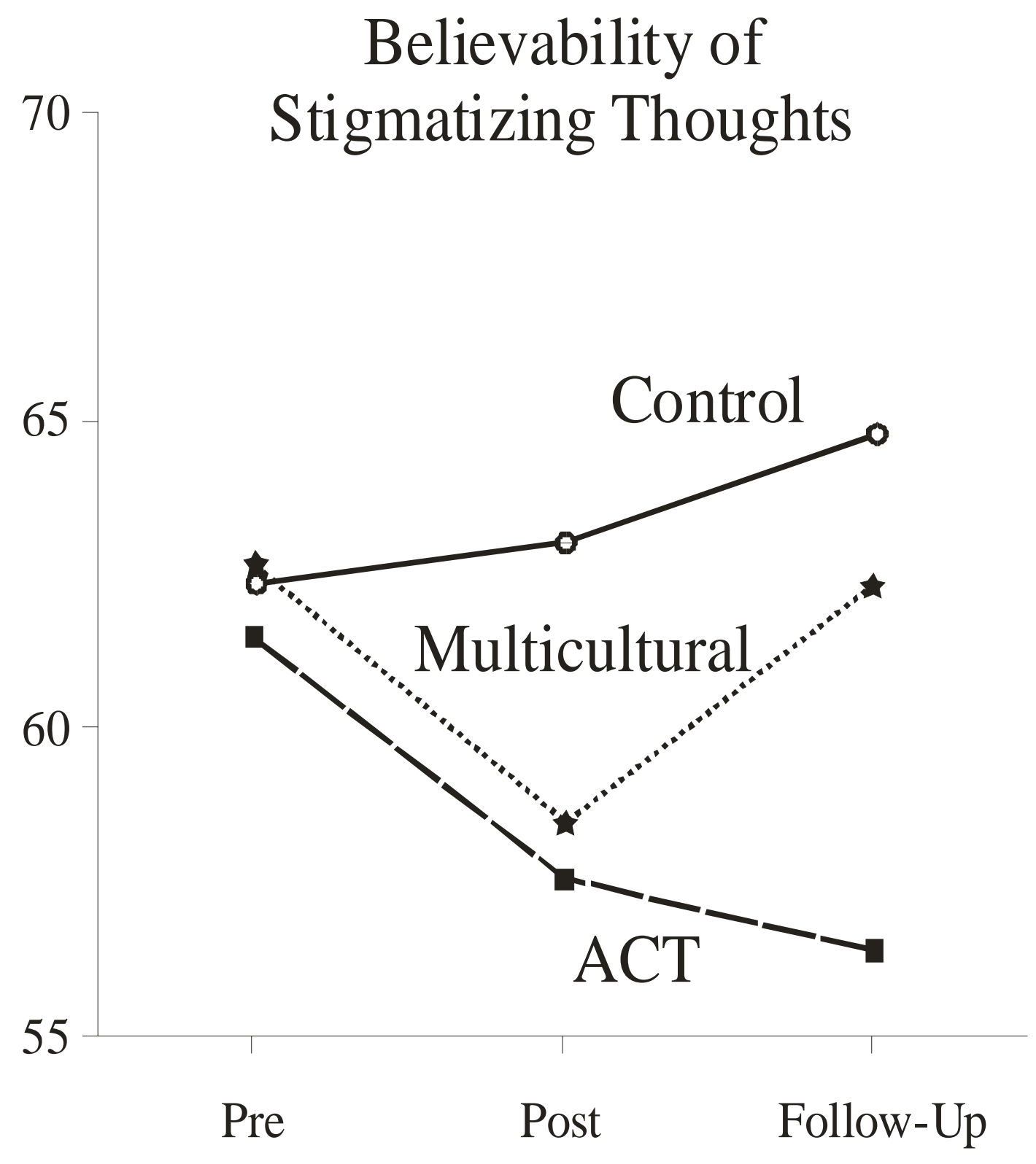

